\title{
Regulation of Neuronal Activity in Hypothalamic Vasopressin Neurons
}

\author{
Toyoaki OHBUCHI, Juhee HAAM, and Jeffrey G. TASKER*
}

Department of Cell and Molecular Biology, Tulane University, New Orleans, LA 70118, U.S.A.

Received July 11, 2015; final version accepted July 28, 2015

\begin{abstract}
Vasopressin is a peptide hormone secreted from the posterior pituitary gland in response to various physiological and/or pathological stimuli, including changes in body fluid volume and osmolality and stress exposure. Vasopressin secretion is controlled by the electrical activity of the vasopressinergic magnocellular neurosecretory cells located in the hypothalamic supraoptic nucleus and paraventricular nucleus. Vasopressin release can occur somatodendritically in the hypothalamus or at the level of pituitary axon terminals. The electrical activity of the vasopressin neurons assumes specific patterns of electrical discharge that are under the control of several factors, including the intrinsic properties of the neuronal membrane and synaptic and hormonal inputs. It is increasingly clear that glial cells perform critical signaling functions that contribute to signal transmission in neural circuits. Astrocytes contribute to neuronal signaling by regulating synaptic and extrasynaptic neurotransmission, as well as by mediating bidirectional neuronal-glial transmission. We recently discovered a novel form of neuronal-glial signaling that exploits the full spatial domain of astrocytes to transmit dendritic retrograde signals from vasopressin neurons to distal upstream neuronal targets. This retrograde trans-neuronal-glial transmission allows the vasopressin neurons to regulate their synaptic inputs by controlling upstream presynaptic neuron firing, thus providing a powerful means of autocontrol of hormonal output.
\end{abstract}

KEYWORDS: glia, astrocyte, hypothalamus, neuron, synapse, vasopressin, supraoptic, paraventricular

\section{Introduction}

The hypothalamo-neurohypophysial system is comprised of magnocellular neuroendocrine cells whose large cell bodies reside in the hypothalamus and whose axons and axon terminals form the pituitary stalk and the neurohypophysis, also known as the posterior lobe of the pituitary gland. This system has served as a model hypothalamic neurosecretory system due to its well-characterized structural, physiological, and behavioral organization. Magnocellular neurons are located in the hypothalamic supraoptic nucleus (SON) and paraventricular nucleus (PVN) and are grouped into two different types of neurons, vasopressin and oxytocin neurons, based on the neuropeptides they synthesize. Oxytocin and vasopressin are secreted as hormones into the bloodstream from the magnocellular axon terminals in the posterior pituitary and are released as neuromodulators from the magnocellular dendrites in the SON and PVN. Oxytocin and vasopressin release is a function of the electrical activity of the oxytocin and vasopressin neurons in the hypothalamus. The electrical activity of the neurons assumes specific patterns of electrical discharge that are under the control of several factors, including the intrinsic properties of the oxytocin and vasopressin neuronal membrane, synaptic inputs, hormone modulation, and neuronal-glial signaling. Here, we provide a general overview of the vasopressin neurosecretory system and discuss the neuronal-glial interactions that regulate the vasopressin neurons.

\section{Vasopressin production and release}

Vasopressin and oxytocin are nine amino acid-long neuropeptides that differ by only two amino acids (Fig. 1). These two neuropeptides are synthesized in SON and PVN magnocellular neurons from precursor peptides that include vasopressin- and oxytocin-associated neurophysin, respectively. After production, the vasopressin and oxytocin precursors are packaged into secretory granules and transported down the axons to the posterior lobe of the pituitary gland [1]. During axon transport, the precursors are processed to produce vasopressin and oxytocin and, once arrived at the axon terminals in the posterior pituitary, these final hormone products are released into the bloodstream in response to action potentials generated in the magnocellular neurons in the hypothalamus and transmitted to the pituitary nerve terminals [1]. In addition to secretion from the pituitary terminals into the systemic blood circulation, vasopressin and oxytocin are also released within the hypothalamic SON and PVN from the dendrites and cell bodies of the magnocellular neurons [2]. 
Vasopressin

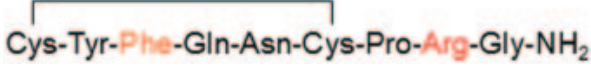

Oxytocin

Cys-Tyr-lle-GIn-Asn-Cys-Pro-Leu-Gly-NH

Fig. 1. Amino-acid sequences of vasopressin and oxytocin. Vasopressin and Oxytocin are both 9-amino-acid peptides that differ by only two amino acids.

\section{Vasopressin receptors}

There are three types of vasopressin receptors, V1a, V1b, and V2 receptors, all of which are G protein-coupled receptors. The V1a and V1b receptors are coupled to Gq/11, whereas the V2 receptor is coupled to Gs (Fig. 2). The physiology and distribution of the receptors are distinct. The V1a receptors are expressed in vascular smooth muscles, where their activation has been shown to cause vasoconstriction, and in different parts of the brain, such as in the olfactory bulb, hippocampus, PVN and suprachiasmatic nucleus (SCN) [3-5]. The V1b receptors are expressed predominantly in the anterior pituitary and are involved in the activation of the hypothalamic-pituitary-adrenal (HPA) axis [6,7], but are also expressed, to a lesser degree, throughout the brain [8]. The V2 receptors are expressed primarily in the kidney, where they mediate vasopressin's critical role in controlling water reabsorption [9], but they have also recently been revealed to contribute to cell volume regulation in vasopressin neurons in the hypothalamus [10].

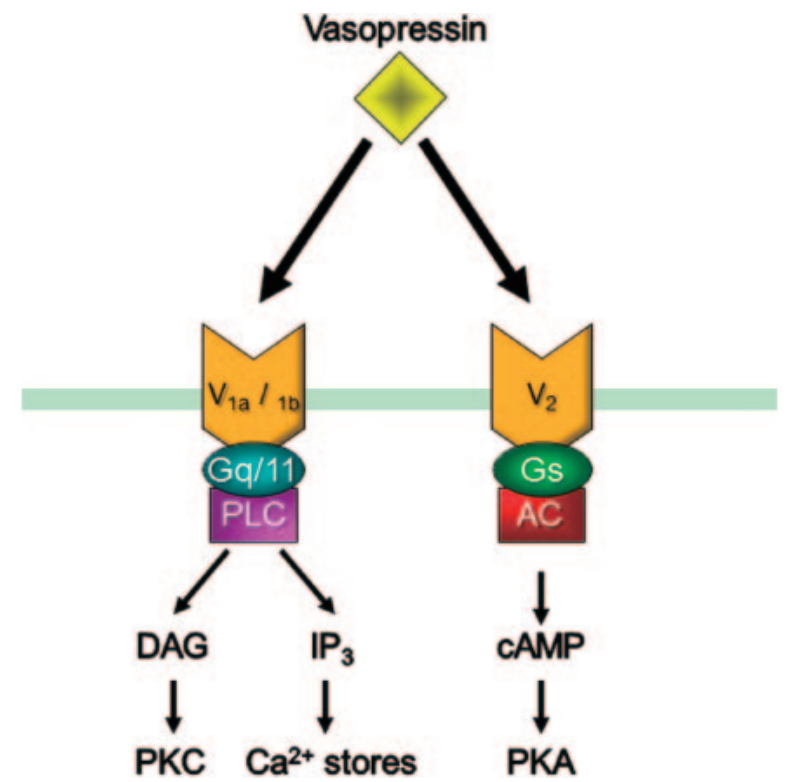

Fig. 2. Vasopressin receptors. There are three known vasopressin receptors, V1a, V1b and V2 receptors, all of which are G proteincoupled receptors. V1a and V1b are coupled to Gq/11 and the IP3/DAG signaling pathway, and V2 receptors are coupled to Gs and the cAMP signaling pathway.

\section{The role of vasopressin}

Vasopressin plays a critical role in fluid homeostasis by controlling blood osmolality, volume and pressure. The secretion of vasopressin from the posterior pituitary is stimulated by high plasma osmolality, hypovolemia, and low arterial blood pressure, and results in a decrease in blood osmolality and an increase in blood volume and pressure. Vasopressin decreases urine volume by activating V2 receptors in the distal nephron of the kidney, which stimulates water absorption. The activation of the $\mathrm{V} 2$ receptor induces the expression and insertion into the membrane of a water channel, aquaporin-2, which causes an increase in water reabsorption in the kidney's collecting duct system [11]. Vasopressin also modulates drinking behavior, which further contributes to the regulation of fluid homeostasis. Furthermore, as mentioned before, vasopressin also has a vasoconstrictive effect via activation of arterial V1a receptors, although this effect requires unusually high circulating levels of the peptide [12].

Vasopressin also stimulates anterior pituitary corticotrope cells to contribute to the activation of the hypothalamicpituitary-adrenal (HPA) axis neuroendocrine response to stress [13,14]. Stress typically activates parvocellular corticotropin-releasing hormone (CRH) neurons in the PVN, inducing the secretion of $\mathrm{CRH}$ into the pituitary portal circulation and the $\mathrm{CRH}$-induced secretion of adrenocorticotropic hormone (ACTH) into the bloodstream from 
corticotrope cells in the anterior pituitary. Circulating ACTH stimulates the synthesis and secretion into the blood of glucocorticoids, corticosterone in rodents and cortisol in primates, by the adrenal glands. Under certain conditions, such as during chronic stress, CRH-synthesizing cells in the PVN co-synthesize and co-secrete vasopressin with $\mathrm{CRH}$ into the portal circulation, where it interacts with vasopressin receptors in the anterior pituitary to facilitate CRH-induced ACTH secretion [15]. Vasopressin synthesized in the magnocellular neurons of the SON and PVN can also contribute to ACTH secretion from the anterior pituitary [15-18]. Thus, vasopressin secreted by the magnocellular axon terminals in the posterior pituitary can access the corticotropes of the anterior pituitary and stimulate ACTH release [19]. It was thought that the upregulation of vasopressin expression in $\mathrm{CRH}$ neurons and of vasopressin secretion during chronic stress might be responsible for the HPA hypersensitivity observed following chronic stress exposure, but it now appears that vasopressin does not mediate the chronic stress-induced HPA hypersensitivity, but rather its chronic stress regulation may contribute to other aspects of stress adaptation of the HPA axis [20].

\section{Electrical activity of vasopressin neurons}

\subsection{Burst firing properties of magnocellular neurons}

Both the vasopressin and oxytocin magnocellular neurons display characteristic bursting patterns of electrical discharge, although the two neuropeptide-expressing cell types differ in the patterns of bursting activity that they generate and in the cellular mechanisms that contribute to burst generation. During parturition and the suckling-induced milk-ejection reflex, oxytocin neurons display intermittent trains of high-frequency action potentials every 5 to 10 minutes. These high-frequency spike discharges attain frequencies of about $100 \mathrm{~Hz}$ and last from 1 to 3 seconds. The synchronization of these bursts to within approximately 500 milliseconds among the oxytocin neurons distributed in the bilateral PVN and SON (i.e., in four different locations in the hypothalamus) results in the pulsatile secretion of oxytocin into the blood from the oxytocin axon terminals in the posterior pituitary. The pulsatile release of oxytocin into the blood every 5 to 10 minutes causes the intermittent, oxytocin receptor-mediated contraction of smooth muscle cells in the mammary glands and uterus, which elicits rhythmic milk ejection, or milk letdown, during the suckling stimulus and uterine contractions during parturition [21].

Vasopressin neurons are activated by vascular hypertonic or hypovolemic stimulation to assume a bursting pattern of action-potential discharge that differs from that of oxytocin neurons. Activated vasopressin neurons initially display a tonic increase in action-potential frequency, which evolves into a phasic pattern of action-potential firing. The phasic firing pattern of vasopressin neurons is usually characterized by long bursts of action potentials, lasting from several seconds to one or more minutes, followed by approximately equal periods of silence or very low-frequency firing. The action-potential bursts are characteristically of lower frequency than the oxytocin neuron bursts, usually attaining peak frequencies of $10-20 \mathrm{~Hz}$ at the start of the bursts and mean frequencies of less than $10 \mathrm{~Hz}$ [22]. Unlike the highfrequency discharges of oxytocin neurons, the phasic action-potential discharges in vasopressin neurons are asynchronous among the vasopressin neurons distributed in the SON and PVN. Therefore, while the increased secretion of vasopressin from individual vasopressin neurons is pulsatile due to the vasopressin neuron phasic firing, the collective release from the asynchronous bursting of the thousands of vasopressin neurons results in an overall tonic increase in vasopressin secretion into the bloodstream [23].

\subsection{Regulation of vasopressin neuron firing by intrinsic membrane properties}

The synaptic innervation of both the vasopressin neurons and oxytocin neurons is critical for triggering their activation under different physiological conditions, but the intrinsic membrane properties of these neurons, especially the vasopressin neurons, regulate their excitability and sculpt their patterns of electrical activity. The depolarizing afterpotential (DAP) is a well-known intrinsic property of vasopressin neurons and, to a lesser extent, oxytocin neurons [24]. The DAP positively modulates the excitability of vasopressin neurons by providing the building block responsible for constructing the depolarization necessary to sustain phasic burst generation. The activation of the DAP is dependent on the depolarization of the membrane, usually during an action potential, and the influx of $\mathrm{Ca}^{2+}$ through high-voltageactivated $\mathrm{Ca}^{2+}$ channels $[25,26]$. DAPs play a critical role in the action-potential bursts in vasopressin neurons by summating when generated in rapid succession to form a depolarizing plateau potential, which provides the sustained membrane depolarization necessary for the repetitive spiking that comprises the burst [27-29]. In addition, the inhibition of the DAP by dynorphin released from the vasopressin neuron dendrites during the repetitive spiking contributes to the termination of the bursts [30]. The hyperpolarizing afterpotential (HAP) is an intrinsic inhibitory mechanism that is dependent on a rapid $\mathrm{Ca}^{2+}$-activated $\mathrm{K}^{+}$conductance that is generated by $\mathrm{Ca}^{2+}$ influx during action potentials. By hyperpolarizing the membrane after each action potential, the HAP limits the frequency at which action potentials can be generated within bursts [31,32]. The after-hyperpolarizing potential (AHP) is another intrinsic inhibitory mechanism in vasopressin neurons that, like the HAP, is mediated by a $\mathrm{Ca}^{2+}$-activated $\mathrm{K}^{+}$conductance, but the AHP is generated by the accumulation of intracellular $\mathrm{Ca}^{2+}$ that occurs during a train of successive action potentials, rather than by a single action potential. Because the AHP is mediated by the cumulative effect of $\mathrm{Ca}^{2+}$ influx during each action potential, the duration and amplitude of the resulting membrane hyperpolarization is dependent on the number and frequency of the action potentials, more and higher-frequency action potentials producing a larger 
AHP. The AHP inhibits the prolonged firing of vasopressin neurons, and is thus an intrinsic mechanism that contributes to the termination of each action-potential burst [31-33], although other unknown mechanisms prolong the inter-burst period of silence for seconds to minutes.

\subsection{Postsynaptic modulation of vasopressin neurons}

Vasopressin neuronal activity is regulated by many different neuropeptides and neuromodulators, such as apelin, pituitary adenylate cyclase activating polypeptide, and brain-derived neurotrophic factor. The activity of vasopressin neurons is also regulated by several humoral factors, such as hyper-osmolality, temperature, low $\mathrm{pH}$, and circulating hormones. In addition, vasopressin neurons are autoregulated by vasopressin, which is released from the somata and dendrites of the vasopressin neurons [34-36]. The mechanisms that induce somato-dendritic release are often independent of the axonal release of neuropeptides into the blood stream. Certain stimuli can induce dendritic release of vasopressin and oxytocin without causing electrical firing of the neurons or neurohormone release from the axon terminals. Previous studies suggested that the somato-dendritic release of vasopressin is induced by activity-dependent depolarization and by $\mathrm{Ca}^{2+}$ mobilization from the intracellular stores, and can last several hours [2,37]. The dendritic release of vasopressin has been reported to be stimulated by glutamate, oestradiol, hypo-osmolality, ghrelin and vasopressin itself $[10,38,39,59]$. The broad array of postsynaptic modulators of vasopressin neuron activity are shown in Figure 3.

\section{vasopressin neuron}

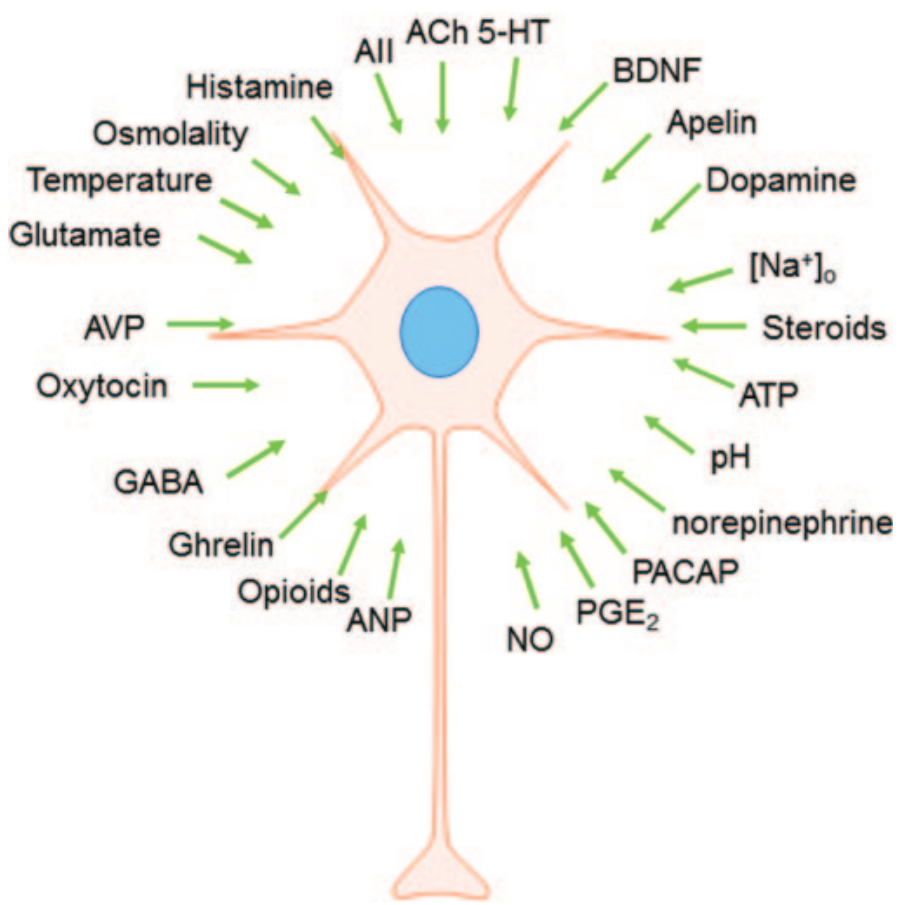

Fig. 3. Known modulators of vasopressin neurons: ACh, acetylcholine; 5-HT, serotonin; AII, angiotensin II; ATP, adenosine triphosphate; $\mathrm{ANP}$, atrial natriuretic peptide; $\mathrm{NO}$, nitric oxide; $\mathrm{PGE}_{2}$, prostaglandin $\mathrm{E}_{2}$; PACAP, pituitary adenylate cyclaseactivating polypeptide; BDNF, brain-derived neurotrophic factor.

\subsection{Glutamatergic and GABAergic synaptic regulation of vasopressin neurons}

Glutamate and GABA are the main neurotransmitters in the SON and PVN. Glutamate is an excitatory neurotransmitter that acts either at ionotropic glutamate receptors ( $\alpha$-amino-3-hydroxy-5-methyl-4-isoxazolepropionic acid (AMPA), kainate and $N$-methyl-D-aspartate (NMDA)) or at metabotropic glutamate receptors (mGluRs). All three ionotropic glutamate receptors are non-selective cation channels that are permeable to $\mathrm{K}^{+}, \mathrm{Na}^{+}$and, in the case of NMDA and some AMPA receptors, $\mathrm{Ca}^{2+}$. Opening of the glutamate receptor channels, therefore, generates excitatory synaptic currents. Previous studies have shown that the PVN neurons receive glutamatergic synaptic inputs from local hypothalamic areas such as the dorsomedial hypothalamus and the perifornical area [40,41]. GABA is the neurotransmitter that accounts for more than $50 \%$ of the total synaptic inputs to vasopressin neurons. There are two types of $\mathrm{GABA}$ receptors, the ionotropic $\mathrm{GABA}_{\mathrm{A}}$ receptors and the metabotropic $\mathrm{GABA}_{\mathrm{B}}$ receptors. The $\mathrm{GABA}_{\mathrm{A}}$ receptor forms an ion channel that is permeable to $\mathrm{Cl}^{-}$, and therefore the polarity of GABAergic synaptic currents depends on the intracellular and extracellular concentrations of $\mathrm{Cl}^{-}$. The intracellular $\mathrm{Cl}^{-}$concentration in neurons is 
determined by three different types of chloride co-transporters, potassium-chloride co-transporter 2 (KCC2), and sodium-potassium-chloride co-transporter 1 (NKCC1) and 2 (NKCC2). $\mathrm{KCC} 2$ is a $\mathrm{Cl}^{-}$exporter that decreases the intracellular $\mathrm{Cl}^{-}$concentration using the $\mathrm{K}^{+}$concentration gradient, whereas $\mathrm{NKCC} 1$ and $\mathrm{NKCC}^{2}$ are $\mathrm{Cl}^{-}$importers that increase the intracellular $\mathrm{Cl}^{-}$concentration using the $\mathrm{Na}^{+}$concentration gradient $[42,43]$. GABA is generally inhibitory in mature neurons due to a high expression of the $\mathrm{Cl}^{-}$exporter $\mathrm{KCC} 2$. However, in vasopressin-expressing, but not in oxytocin-expressing, magnocellular neurons, GABA is excitatory under different conditions due to a reduced relative contribution of $\mathrm{KCC} 2$ compared to the $\mathrm{NKCC} 1$ and $\mathrm{NKCC} 2 \mathrm{Cl}^{-}$importers [44-46].

The glutamatergic and GABAergic synaptic inputs to vasopressin and oxytocin neurons are regulated presynaptically by a diverse array of neuromodulators, such as endocannabinoids, nitric oxide, opioids, and hyper-osmolality. In addition, vasopressin itself modulates vasopressin neurons both postsynaptically by acting in an autocrine fashion directly at receptors located on the vasopressin neurons and presynaptically by acting in a paracrine fashion at receptors on presynaptic terminals to modulate the probability of neurotransmitter release onto the vasopressin cells [47,48].

\subsection{The role of glia in the regulation of vasopressin neurons}

In recent years, increasing evidence has shown the bidirectional communication between glial cells and neurons, underscoring a long-overlooked role of glial cells in the regulation of neuronal activity. Glial cells are classified into two major types, microglia and macroglia. Microglia are macrophagic cells in the central nervous system that are responsible for inflammatory responses. Macroglia include several different types of cells such as astrocytes, oligodendrocytes and ependymal cells. Astrocytes are in close proximity to neurons, and play critical roles in the regulation of neuronal activity $[49,50]$.

Glia regulate neuronal excitability in several ways. First, astrocytes take up synaptically released neurotransmitters and neuropeptides, thus regulating the amount and spatial diffusion of extracellular signaling molecules [51]. Glia also modulate neuronal activity directly by releasing gliotransmitters, such as ATP, taurine, and D-serine [52-55], which bind to receptors on neighboring neurons to alter their electrical signaling. Glia also control neuronal cell activity by regulating extracellular ionic concentrations. For example, astrocytes have been shown to play a critical role in maintaining a low extracellular $\mathrm{K}^{+}$concentration, which is the main determinant of the resting potential of neurons, by taking up $\mathrm{K}^{+}$emitted by neurons during periods of high electrical activity. The astrocyte-mediated $\mathrm{K}^{+}$homeostasis is regulated by $\mathrm{K}^{+}$channels expressed in the astrocytes and gap junctions that interconnect astrocytes [56-58]. Glia also contribute to the maintenance of proper extracellular concentration of $\mathrm{Na}^{+}, \mathrm{Cl}^{-}$and $\mathrm{H}^{+}$using various ion channels, transporters and pumps. Finally, we recently discovered a novel form of neuronal-glial communication, in which astrocytes serve as an intercellular intermediate in the retrograde communication between two neurons [59]. This form of neuronal-glial communication allows neurons to signal retrogradely to presynaptic neurons at a distance to alter their action potential firing.

Although glia lack the capacity to generate action potentials, they can react to external signals by increasing their intracellular calcium concentration. Glia express various receptors to respond to extracellularly released transmitters, such as glutamate, GABA, histamine, acetylcholine, norepinephrine, and vasopressin. In addition, glia receive intracellular signals from other glial cells through gap junctions, which allows a fast diffusion of calcium ions or inositol triphosphate and transmission of calcium waves through networks of interconnected cells. It was recently shown that astrocytes also express V1a receptors and respond to dendritically released vasopressin in the PVN with an increase in intracellular calcium concentration [59].

In the hypothalamus, the function of astrocytes has been extensively studied under specialized physiological conditions, such as during lactation and dehydration. Glutamate release onto the hypothalamic magnocellular neurons is negatively modulated by autocrine or paracrine activation of mGluRs at presynaptic glutamate axon terminals (Fig. 4) [60], although the glutamate access to presynaptic mGluRs is limited by glial uptake under normal conditions. During lactation and dehydration, the SON and PVN undergo dramatic morphological changes, which include the retraction of astrocytic processes from around magnocellular neurons and a decrease in the astrocytic coverage of neuronal synapses onto the magnocellular neurons [61]. Due to the decrease in astrocytic coverage, the level of clearance of glutamate released from axon terminals is reduced, causing an increase in the concentration and spatial diffusion of extracellular glutamate. The elevated extracellular glutamate under these conditions of decreased glutamate clearance increases the activation of mGluRs at presynaptic terminals, which causes a decrease in glutamate release (Fig. 4) [53, 62].

The magnocellular neurons synthesize and release endogenous cannabinoid messengers, or endocannabinoids, from their dendrites as a result of an increase in spiking and back-propagation of spikes into the dendrites [48], and in response to stress-induced glucocorticoid secretion and activation of membrane-associated glucocorticoid receptors $[63,64]$. There are two main endocannabinoids, $N$-arachidonoylethanolamide (anandamide) and 2-arachidonoylglycerol (2-AG). Anandamide is released continuously at GABA synapses and activates presynaptic type 1 cannabinoid (CB1) receptors to exert a tonic suppression of GABA release onto the magnocellular neurons [65]. The endocannabinoid 2-AG, on the other hand, is induced in the magnocellular neurons by electrical activity and by glucocorticoid actions, and phasically activates CB1 receptors on presynaptic glutamate terminals to elicit an ondemand suppression of synaptic excitation. Astrocytes control the synapse specificity of 2-AG, restricting its actions to 


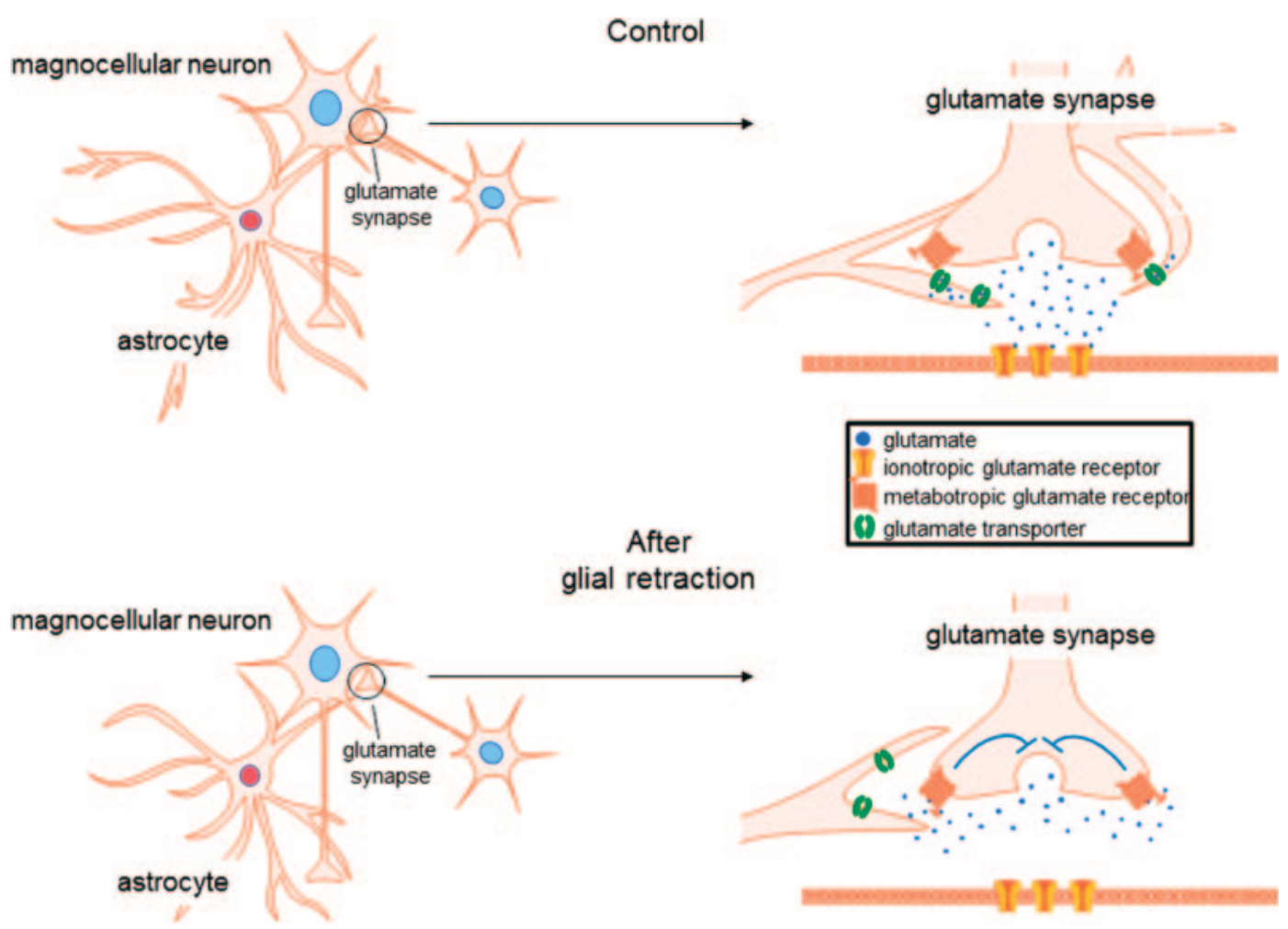

Fig. 4. Glial regulation of glutamate modulation of magnocellular neurons. Under baseline conditions, astrocytes regulate the activation of presynaptic metabotropic glutamate receptors by uptake of extracellular glutamate by glial transporters, which prevents glutamate access to the receptors. Glial retraction uncovers the presynaptic receptors and allows their activation by glutamate, which provides a feedback autoinhibition of glutamate release.

glutamate synapses under normal conditions. However, under conditions of glial retraction and loss of glial uptake, 2AG also activates CB1 receptors on GABA terminals and suppresses GABA release (Fig. 5) [65]. This suggests that 2AG is synthesized and released at glutamate synapses onto magnocellular neurons, and it spills over onto GABA synapses when astrocytes retract to allow diffusion away from the glutamate synapses. Interestingly, the tonic endocannabinoid (i.e., anandamide) activation of CB1 receptors at GABA synapses, and lack of tonic CB1 activation at glutamate synapses, is unaffected by manipulation of the astrocytes, suggesting that the anandamide actions are not restricted to GABA synapses by astrocytic buffering mechanisms and may, therefore, use a mechanism of transport from the postsynaptic membrane to the presynaptic CB1 receptors that differs from that of 2-AG, since it does not involve astrocyte-regulated diffusion through the extracellular space.

Glial cells also modulate hypothalamic magnocellular neurons by releasing the gliotransmitters ATP, taurine, and D-serine. Taurine inhibits magnocellular neurons and decreases the secretion of vasopressin and oxytocin, whereas ATP has an excitatory effect on the magnocellular neurons [54,55,66-68]. D-serine released by astrocytes serves as a co-agonist at NMDA receptors on the magnocellular neurons and permits the induction of long-term potentiation in these cells [69].

We recently discovered yet another form of neuronal-glial interaction when investigating the effects of the orexigenic peptide ghrelin on magnocellular neuroendocrine cells [59], which is illustrated in Fig. 6. We found that vasopressin neurons, but not oxytocin neurons, respond to ghrelin with an increase in their GABAergic synaptic inputs, which was mediated by ghrelin stimulation of spiking in presynaptic GABA neurons. However, the stimulation of upstream GABA neurons was triggered by the activation of postsynaptic ghrelin receptors, located on the vasopressin neurons, and required the release of vasopressin from the vasopressin neuron dendrites. The dendritically released vasopressin stimulated a calcium response in astrocytes in the PVN via the activation of V1a receptors. This led to the release of ATP by the astrocytes, which stimulated presynaptic GABA neurons to generate action potentials and release GABA onto the vasopressin neurons, thus closing a retrograde signaling loop. Thus, our findings provide compelling evidence for the integration of astrocytes into a retrograde circuit that allows vasopressin neurons in the PVN to control their upstream afferent GABA neuron partners. Because the GABA neurons presynaptic to the PVN vasopressin neurons are located in the perinuclear zone surrounding the PVN [70], this circuit provides an anatomical substrate for retrograde signaling by the vasopressin neurons to distal upstream neurons. Furthermore, this retrograde neuronal-glialneuronal circuit is not unique to the vasopressin neurons, as we have preliminary evidence for a similar circuit that controls the norepinephrine activation of CRH neurons of the PVN [71]. 


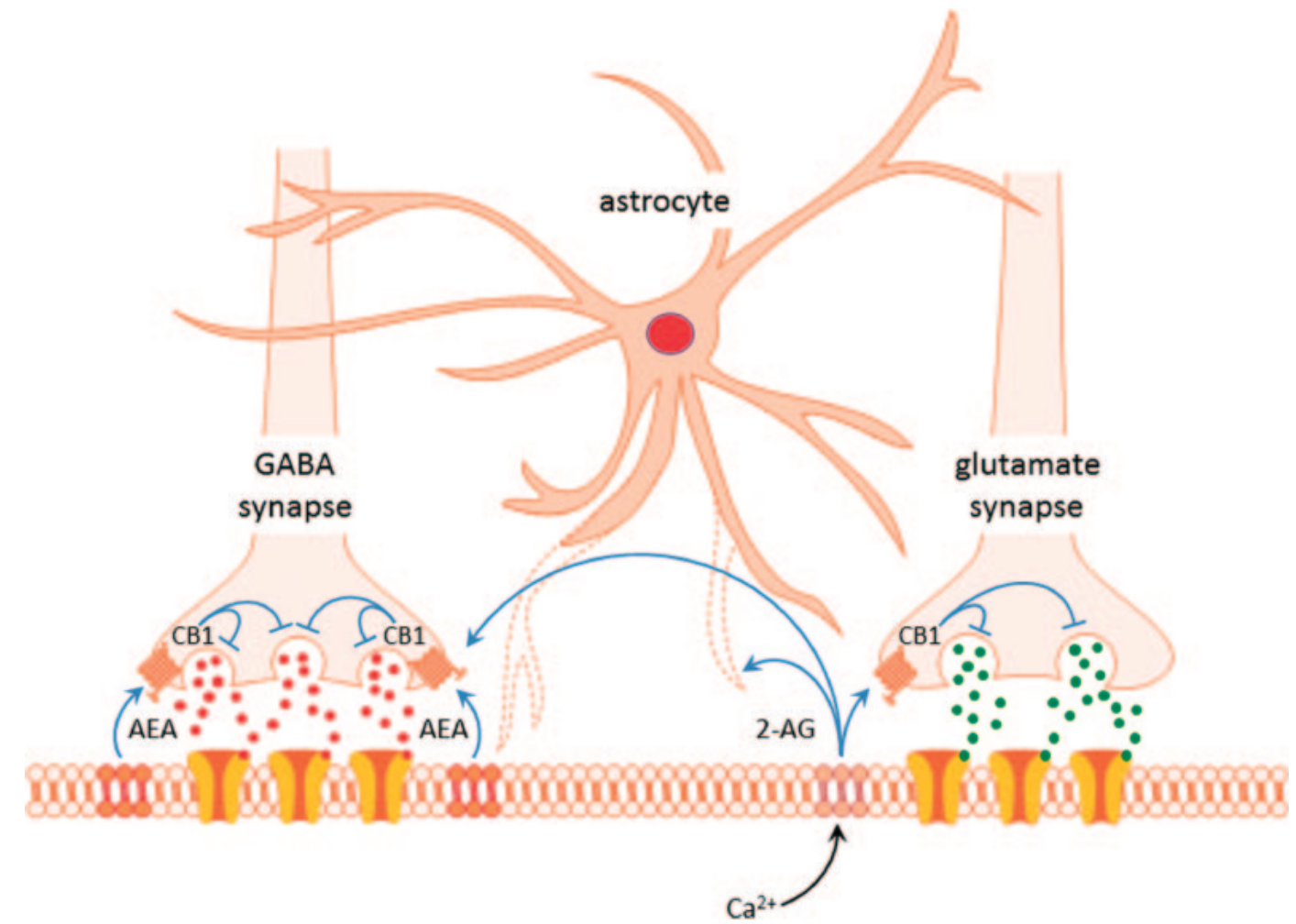

Fig. 5. Synapse-specific actions of endocannabinoids controlled by glial coverage of synapses. Tonic release of anandamide (AEA) provides a retrograde inhibitory tone on GABA release by activating CB1 receptors specifically at GABA synapses on magnocellular neurons. Release of 2-AG evoked by $\mathrm{Ca}$-dependent signaling retrogradely suppresses glutamate release via CB1 receptor activation specifically at glutamatergic excitatory synapses. Physiological or pathological stimulation leads to retraction of astrocyte processes, which allows 2-AG spillover onto GABA synapses and further suppression of GABA release. Tonic AEA actions are not regulated by glial coverage and are limited to GABA synapses.

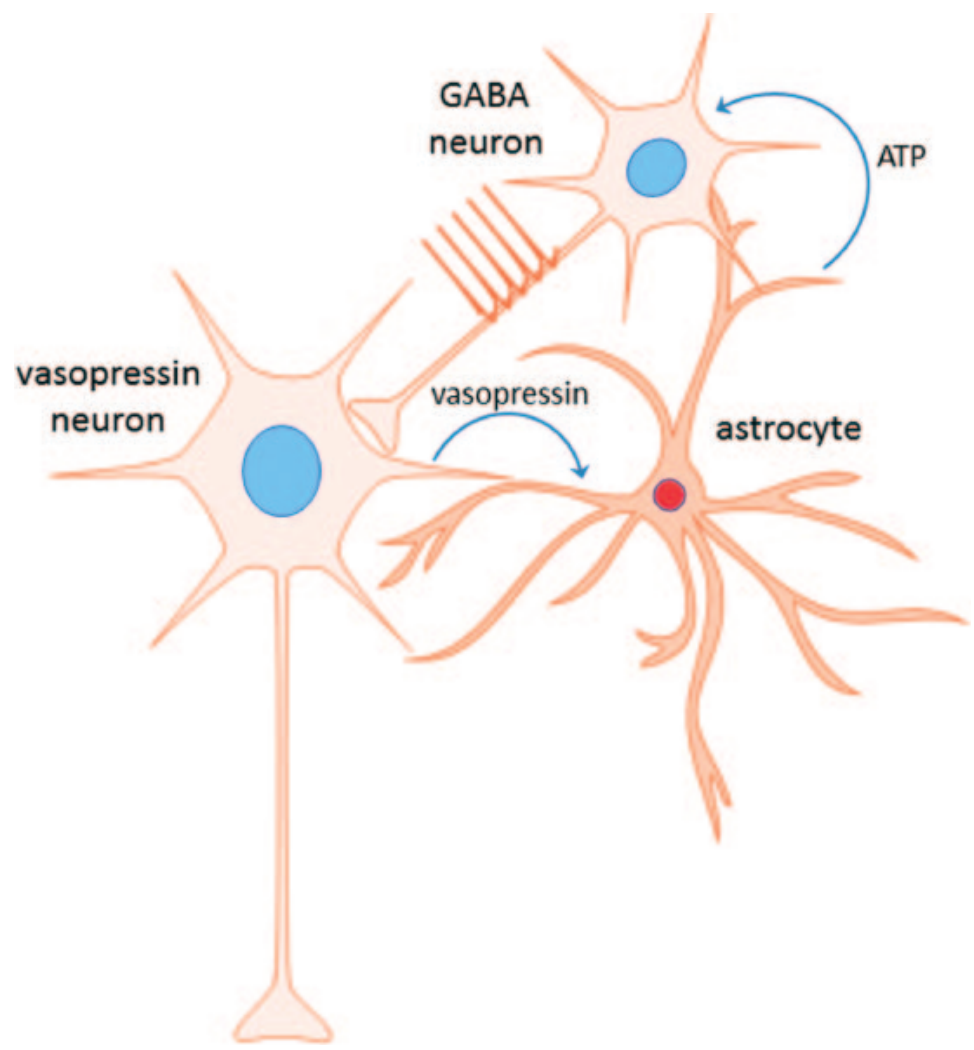

Fig. 6. Model of putative retrograde neuronal-glial-neuronal circuit. Dendritic release of vasopressin stimulates astrocytes, which signal to presynaptic GABA neurons via ATP release. The upstream GABA neurons respond with action potentials and an increase in GABA release back on the vasopressin neurons. 


\section{Concluding remarks}

Electrophysiological investigations of the hypothalamic magnocellular neuroendocrine neurons have revealed a growing number of modes of neuronal modulation of the vasopressin- and oxytocin-secreting cells. In addition to intrinsic regulation and synaptic modulation, magnocellular neurons are under significant control by glial cells. Thus, astrocytes perform critical signaling functions that contribute to neurotransmission and plasticity in the magnocellular neural circuits, such that they can no longer be relegated to a purely supporting role in signal transmission. The magnocellular neuroendocrine system has emerged as a model system for discovery in the area of neuronal-glial interactions, and recent novel findings in this system open up new vistas for the study of the glial control of neural circuits.

Disclosure of Summary; The authors have nothing to disclose.

\section{REFERENCES}

[1] Brownstein MJ, Russell JT, Gainer H (1980) Synthesis, transport, and release of posterior pituitary hormones. Science 207:373-378.

[2] Ludwig M, Sabatier N, Bull PM, Landgraf R, Dayanithi G, Leng G (2002) Intracellular calcium stores regulate activitydependent neuropeptide release from dendrites. Nature 418:85-89.

[3] Tribollet E, Barberis C, Dubois-Dauphin M, Dreifuss JJ (1992) Localization and characterization of binding sites for vasopressin and oxytocin in the brain of the guinea pig. Brain Res 589:15-23.

[4] Ostrowski NL, Lolait SJ, Young WS $3^{\text {rd }}$ (1994) Cellular localization of vasopressin V1a receptor messenger ribonucleic acid in adult male rat brain, pineal, and brain vasculature. Endocrinology, 135:1511-1528.

[5] Tobin VA, Hashimoto H, Wacker DW, Takayanagi Y, Langnaese K, Caquineau C, Noack J, Landgraf R, Onaka T, Leng G, Meddle SL, Engelmann M, Ludwig M (2010) An intrinsic vasopressin system in the olfactory bulb is involved in social recognition. Nature 464:413-437.

[6] Hurbin A, Boissin-Agasse L, Orcel H, Rabié A, Joux N, Desarménien MG, Richard P, Moos FC (1998) The V1a and V1b, but not V2, vasopressin receptor genes are expressed in the supraoptic nucleus of the rat hypothalamus, and the transcripts are essentially colocalized in the vasopressinergic magnocellular neurons. Endocrinology 139:4701-4707.

[7] Hernando F, Schoots O, Lolait SJ, Burbach JP (2001) Immunohistochemical localization of the vasopressin V1b receptor in the rat brain and pituitary gland: anatomical support for its involvement in the central effects of vasopressin. Endocrinology 142:1659-1668.

[8] Young WS, Li J, Wersinger SR, Palkovits M (2006) The vasopressin 1b receptor is prominent in the hippocampal area CA2 where it is unaffected by restraint stress or adrenalectomy. Neuroscience 143:1031-1039.

[9] Erlenbach I, Wess J (1998) Molecular basis of V2 vasopressin receptor/Gs coupling selectivity. J Biol Chem 273:2654926558.

[10] Sato K, Numata T, Saito T, Ueta Y, Okada Y (2011) V2 receptor-mediated autocrine role of somatodendritic release of AVP in rat vasopressin neurons under hypo-osmotic conditions. Sci Signal 4: ra5.

[11] Knepper MA, Inoue T (1997) Regulation of aquaporin-2 water channel trafficking by vasopressin. Curr Opin Cell Biol 9:560-564

[12] Johnston CI (1985) Vasopressin in circulatory control and hypertension. J Hypertens 3:557-569.

[13] Krisch B (1978) Altered pattern of vasopressin distribution in the hypothalamus of rats subjected to immobilization stress. An immunohistochemical study. Cell Tissue Res 189:267-275.

[14] Jiang YQ, Kawashima H, Iwasaki Y, Uchida K, Sugimoto K, Itoi K (2004) Differential effects of forced swim-stress on the corticotropin-releasing hormone and vasopressin gene transcription in the parvocellular division of the paraventricular nucleus of rat hypothalamus. Neurosci Lett 358:201-204.

[15] Antoni FA (1993) Vasopressinergic control of pituitary adrenocorticotropin secretion comes of age. Front Neuroendocrinol 14:76-122.

[16] Holmes MC, Antoni FA, Aguilera G, Catt KJ (1986) Magnocellular axons in passage through the median eminence release vasopressin. Nature 319:326-329.

[17] Irvine CH, Alexander SL, Donald RA (1989) Effect of an osmotic stimulus on the secretion of arginine vasopressin and adrenocorticotropin in the horse. Endocrinology 124:3102-3108.

[18] Aguilera G (1994) Regulation of pituitary ACTH secretion during chronic stress. Front Neuroendocrinol 15:321-350.

[19] Page RB (1982) Pituitary blood flow. Am J Physiol 243:E427-E442.

[20] Chen J, Young S, Subburaju S, Sheppard J, Kiss A, Atkinson H, Wood S, Lightman S, Serradeil-Le Gal C, Aguilera G (2008) Vasopressin does not mediate hypersensitivity of the hypothalamic pituitary adrenal axis during chronic stress. Ann N Y Acad Sci 1148:349-359.

[21] Wakerley JB, Lincoln DW (1973) The milk-ejection reflex of the rat: a 20- to 40-fold acceleration in the firing of paraventricular neurones during oxytocin release. J Endocrinol 57:477-493.

[22] Wakerley JB, Poulain DA, Dyball RE, Cross BA (1975) Activity of phasic neurosecretory cells during haemorrhage. Nature 258:82-84.

[23] Poulain DA, Wakerley JB (1982) Electrophysiology of hypothalamic magnocellular neurones secreting oxytocin and vasopressin. Neuroscience 7:773-808.

[24] Teruyama R, Armstrong WE (2007) Calcium-dependent fast depolarizing afterpotentials in vasopressin neurons in the rat supraoptic nucleus. J Neurophysiol 98:2612-2621. 
[25] Bourque CW (1986) Calcium-dependent spike after-current induces burst firing in magnocellular neurosecretory cells. Neurosci Lett 70:204-209.

[26] Li Z, Hatton GI (1997) Reduced outward K+ conductances generate depolarizing after-potentials in rat supraoptic nucleus neurones. J Physiol (Lond) 505:95-106.

[27] Hatton GI (1982) Phasic bursting activity of rat paraventricular neurones in the absence of synaptic transmission. $J$ Physiol (Lond) 327:273-284.

[28] Andrew RD, Dudek FE (1983) Burst discharge in mammalian neuroendocrine cells involves an intrinsic regenerative mechanism. Science 221:1050-1052.

[29] Andrew RD, Dudek FE (1984) Analysis of intracellularly recorded phasic bursting by mammalian neuroendocrine cells. J Neurophysiol 51:552-566.

[30] Brown CH, Bourque CW (2004) Autocrine feedback inhibition of plateau potentials terminates phasic bursts in magnocellular neurosecretory cells of the rat supraoptic nucleus. J Physiol (Lond) 557:949-960.

[31] Andrew RD, Dudek FE (1984) Intrinsic inhibition in magnocellular neuroendocrine cells of rat hypothalamus. $J$ Physiol (Lond) 353:171-185.

[32] Bourque CW, Randle JC, Renaud LP (1985) Calcium-dependent potassium conductance in rat supraoptic nucleus neurosecretory neurons. J Neurophysiol 54:1375-1382.

[33] Armstrong WE, Smith BN, Tian M (1994) Electrophysiological characteristics of immunochemically identified rat oxytocin and vasopressin neurones in vitro. J Physiol (Lond) 475:115-128.

[34] Moos F, Freund-Mercier MJ, Guerné Y, Guerné JM, Stoeckel ME, Richard P (1984) Release of oxytocin and vasopressin by magnocellular nuclei in vitro: specific facilitatory effect of oxytocin on its own release. $J$ Endocrinol 102:63-72.

[35] Mason WT, Hatton GI, Ho YW, Chapman C, Robinson IC (1986) Central release of oxytocin, vasopressin and neurophysin by magnocellular neurone depolarization: evidence in slices of guinea pig and rat hypothalamus. Neuroendocrinology 42:311-322.

[36] Pow DV, Morris JF (1989) Dendrites of hypothalamic magnocellular neurons release neurohypophysial peptides by exocytosis. Neuroscience 32:435-439.

[37] Ludwig M, Bull PM, Tobin VA, Sabatier N, Landgraf R, Dayanithi G, Leng G (2005) Regulation of activity-dependent dendritic vasopressin release from rat supraoptic neurones. J Physiol (Lond) 564:515-522.

[38] Wang H, Ward AR, Morris JF (1995) Oestradiol acutely stimulates exocytosis of oxytocin and vasopressin from dendrites and somata of hypothalamic magnocellular neurons. Neuroscience 68:1179-1188.

[39] Morris JF, Christian H, Ma D, Wang H (2000) Dendritic secretion of peptides from hypothalamic magnocellular neurosecretory neurones: a local dynamic control system and its functions. Exp Physiol 85:131S-138S.

[40] Takano S, Negoro H, Honda K, Higuchi T (1992) Lesion and electrophysiological studies on the hypothalamic afferent pathway of the milk ejection reflex in the rat. Neuroscience 50:877-883.

[41] Boudaba C, Schrader LA, Tasker JG (1997) Physiological evidence for local excitatory synaptic circuits in the rat hypothalamus. J Neurophysiol 77:3396-3400.

[42] Payne JA, Stevenson TJ, Donaldson LF (1996) Molecular characterization of a putative K-Cl cotransporter in rat brain. A neuronal-specific isoform. J Biol Chem 271:16245-16252.

[43] Plotkin MD, Kaplan MR, Peterson LN, Gullans SR, Hebert SC, Delpire E (1997) Expression of the Na(+)-K(+)-2Clcotransporter BSC2 in the nervous system. Am J Physiol 272:C173-C183.

[44] Haam J, Popescu IR, Morton LA, Halmos KC, Teruyama R, Ueta Y, Tasker JG (2012) GABA is excitatory in adult vasopressinergic neuroendocrine cells. J Neurosci 32:572-582.

[45] Choe KY, Han SY, Gaub P, Shell B, Voisin DL, Knapp BA, Barker PA, Brown CH, Cunningham JT, Bourque CW (2015) High salt intake increases blood pressure via BDNF-mediated downregulation of KCC2 and impaired baroreflex inhibition of vasopressin neurons. Neuron 85:549-560.

[46] Konopacka A, Qiu J, Yao ST, Greenwood MP, Greenwood M, Lancaster T, Inoue W, Mecawi Ade S, Vechiato FM, de Lima JB, Coletti R, Hoe SZ, Martin A, Lee J, Joseph M, Hindmarch C, Paton J, Antunes-Rodrigues J, Bains J, Murphy D (2015) Osmoregulation requires brain expression of the renal Na-K-2Cl cotransporter NKCC2. J Neurosci 35:5144-5155.

[47] Gouzenes L, Desarmenien MG, Hussy N, Richard P, Moos FC (1998) Vasopressin regularizes the phasic firing pattern of rat hypothalamic magnocellular vasopressin neurons. J Neurosci 18:1879-1885.

[48] Hirasawa M, Mouginot D, Kozoriz MG, Kombian SB, Pittman QJ (2003) Vasopressin differentially modulates non-NMDA receptors in vasopressin and oxytocin neurons in the supraoptic nucleus. J Neurosci 23:4270-4277.

[49] Ventura R, Harris KM (1999) Three-dimensional relationships between hippocampal synapses and astrocytes. $J$ Neurosci 19:6897-6906.

[50] Bushong EA, Martone ME, Ellisman MH (2004) Maturation of astrocyte morphology and the establishment of astrocyte domains during postnatal hippocampal development. Int J Dev Neurosci 22:73-86.

[51] Chaudhry FA, Lehre KP, van Lookeren Campagne M, Ottersen OP, Danbolt NC, Storm-Mathisen J (1995) Glutamate transporters in glial plasma membranes: highly differentiated localizations revealed by quantitative ultrastructural immunocytochemistry. Neuron 15:711-720.

[52] Hassinger TD, Atkinson PB, Strecker GJ, Whalen LR, Dudek FE, Kossel AH, Kater SB (1995) Evidence for glutamatemediated activation of hippocampal neurons by glial calcium waves. $J$ Neurobiol 28:159-170.

[53] Oliet SH, Piet R, Poulain DA (2001) Control of glutamate clearance and synaptic efficacy by glial coverage of neurons. Science 292:923-926.

[54] Hussy N (2002) Glial cells in the hypothalamo-neurohypophysial system: key elements of the regulation of neuronal electrical and secretory activity. Prog Brain Res 139:95-112.

[55] Gordon GR, Baimoukhametova DV, Hewitt SA, Rajapaksha WR, Fisher TE, Bains JS (2005) Norepinephrine triggers release 
of glial ATP to increase postsynaptic efficacy. Nat Neurosci 8:1078-1086.

[56] Price DL, Ludwig JW, Mi H, Schwarz TL, Ellisman MH (2002) Distribution of rSlo $\mathrm{Ca}^{2+}$-activated $\mathrm{K}^{+}$channels in rat astrocyte perivascular endfeet. Brain Res 956:183-193.

[57] Menichella DM, Majdan M, Awatramani R, Goodenough DA, Sirkowski E, Scherer SS, Paul DL (2006) Genetic and physiological evidence that oligodendrocyte gap junctions contribute to spatial buffering of potassium released during neuronal activity. J Neurosci 26:10984-10991.

[58] Chever O, Djukic B, McCarthy KD, Amzica F (2010) Implication of Kir4.1 channel in excess potassium clearance: an in vivo study on anesthetized glial-conditional Kir4.1 knock-out mice. J Neurosci 30:15769-15777.

[59] Haam J, Halmos KC, Tasker JG (2014) Nutritional state-dependent ghrelin activation of vasopressin neurons via retrograde trans-neuronal-glial stimulation of excitatory GABA circuits. J Neurosci 34: 6201-6213.

[60] Schrader LA, Tasker JG (1997) Presynaptic modulation by metabotropic glutamate receptors of excitatory and inhibitory synaptic inputs to hypothalamic magnocellular neurons. J Neurophysiol 77:527-536.

[61] Theodosis DT, Chapman DB, Montagnese C, Poulain DA, Morris JF (1986) Structural plasticity in the hypothalamic supraoptic nucleus at lactation affects oxytocin-, but not vasopressin-secreting neurones. Neuroscience 17:661-678.

[62] Boudaba C, Linn DM, Halmos KC, Tasker JG (2003) Increased tonic activation of presynaptic metabotropic glutamate receptors in the rat supraoptic nucleus following chronic dehydration. $J$ Physiol (Lond) 551:815-823.

[63] Di S, Malcher-Lopes R, Marcheselli VL, Bazan NG, Tasker JG (2005) Rapid glucocorticoid-mediated endocannabinoid release and opposing regulation of glutamate and gamma-aminobutyric acid inputs to hypothalamic magnocellular neurons. Endocrinology 146:4292-4301.

[64] Di S, Boudaba C, Popescu IR, Weng FJ, Harris C, Marcheselli VL, Bazan NG, Tasker JG (2005) Activity-dependent release and actions of endocannabinoids in the rat hypothalamic supraoptic nucleus. J Physiol (Lond) 569:751-760.

[65] Di S, Popescu IR, Tasker JG (2013) Glial control of endocannabinoid heterosynaptic modulation in hypothalamic magnocellular neuroendocrine cells. J Neurosci 33:18331-18342.

[66] Hu B, Bourque CW (1992) NMDA receptor-mediated rhythmic bursting activity in rat supraoptic nucleus neurones in vitro. J Physiol (Lond) 458:667-687.

[67] Panatier A, Oliet SH (2006) Neuron-glia interactions in the hypothalamus. Neuron Glia Biol 2:51-58.

[68] Song Z, Vijayaraghavan S, Sladek CD (2007) ATP increases intracellular calcium in supraoptic neurons by activation of both P2X and P2Y purinergic receptors. Am J Physiol Regul Integr Comp Physiol 292:R423-R431.

[69] Panatier A, Theodosis DT, Mothet JP, Touquet B, Pollegioni L, Poulain DA, Oliet SH (2006) Glia-derived D-serine controls NMDA receptor activity and synaptic memory. Cell 125:775-784.

[70] Boudaba C, Szabó K, Tasker JG (1996) Physiological mapping of local inhibitory inputs to the hypothalamic paraventricular nucleus. J Neurosci 16:7151-7160.

[71] Chen C, Jiang Z, Tasker JG (2014) Noradrenergic activation of CRH neurons via a novel retrograde trans-neuronal-glial circuit. Program No. 78.04. 2014 Neuroscience Meeting Planner, Washington, D.C. 